\title{
Childhood obesity prevention: does policy meet research? Evidence-based reflections upon the spanish case
}

\begin{abstract}
Childhood obesity is a major public health challenge, and its prevalence and severity are increasing worldwide despite the different actions launched. The aim of this article is to critically review to what extent policies developed at different international institutional levels affecting Spain have effectively translated current research into practice as well as to discuss how the available evidence can serve policy makers. A review of reviews on childhood obesity prevention practices was first performed using MEDLINE and ERIC databases. To select the relevant policies, several experts on childhood obesity prevention were consulted. Results show that, on paper, policies comply with current research recommendations, but in practice there is a gap in how to reach these goals as a role overlap between institutions. Actions need more definition, particularly in the procedural and methodological aspects. Policymakers face numerous barriers to work on this direction, one of the most relevant being the difficulty of implementing systemic policies based upon compartmentalised research. Lessons learned in fields such as community development and education might inform this process.
\end{abstract}

Keywords: childhood obesity, prevention, effectiveness, policy, review
Volume 6 Issue 2 - 2017

\author{
Elena Carrillo Álvarez,' Jordi Riera I \\ Romani $^{2}$ \\ 'Department of Health Sciences, Blanquerna-Ramon Llull \\ University, Spain \\ ${ }^{2}$ Faculty of Psychology, Education and Sport Sciences, \\ Blanquerna-Ramon Llull University, Spain
}

Correspondence: Elena Carrillo Álvarez,Associate professor Faculty of Health Sciences, Blanquerna -Ramon Llull University, Spain,Email elenaca@blanquerna.url.edu

Received: June 08, 2017 | Published: August 23, 2017

\section{Introduction}

The WHO and IOTF have already qualified obesity as the $21^{\text {st }}$ century epidemic. Childhood obesity is even more concerning because of the impact that this condition has on youth health and adult life. Implementing preventive actions to reduce obesity has become a priority in most public health agendas. Spain is amongst the European countries with highest prevalence's: one out of two adults and one out of three children are overweight or obese. ${ }^{1}$ In 2013, the WHO's Global Action Plan for the Prevention and Control of NonCommunicable Diseases 2013-2020 set the modest goal of achieving a zero increase in prevalence from 2010 to 2025 . However, in light of the advancement made - no country has yet successfully reversed these trends, ${ }^{2-4}$ even this conservative aim seems challenging. At different levels, several circumstances may explain this difficulty. Here we tap into four of them. First, the controversial understanding of obesity itself; ${ }^{5-7}$ second, the pressure posed by the utterly competitive food industry; ${ }^{6-9}$ third, the very own human nature in biological, psychological, cultural, and social terms; ${ }^{7-11}$ and fourth, the current scientific evidence hierarchy and the difficulty to translate it into actual policy ${ }^{5-14}$ which will be the main focus of this paper. In the first Lancet's Obesity Series published in 2011, the globalization of food systems that led to overconsumption, an expectable outcome of market economies, was posed as the main factor responsible for the increasing burden of obesity. In other words, obesity was seen as the normal response of individuals to the obesogenic environment they find themselves in, and as a consequence, policy and regulatory actions were identified as the most cost-effective means to tackle the problem. Four years after, a second edition under the leadership of Boyd Swinburn identifies further high-priority actions by overcoming some of the more established dichotomies in the phenomenon of obesity: personal versus collective responsibilities, upstream versus downstream drivers for change, treatment versus prevention, or under nutrition versus over nutrition priorities. Obesity is a complex issue, and the fact that little progress has been made between the publication of these two monographers somehow reflects the limitations of looking at obesity in terms of "either/or". ${ }^{15}$ Healthy behaviors are reinforced when policy and environment support healthy choices at the same time that individuals are educated and motivated to make those choices ${ }^{16}$ as attested by the success achieved in the case of other health risks such as tobacco or alcohol. Notwithstanding that, tackling obesity demands broader, more specific actions than the ones used in these cases, as food is indispensable to life and, anthropologically, its connotations for human beings go beyond nutrition and acquire a psychological, social and cultural meaning (among others) that cannot be overlooked. ${ }^{1-18}$ All the previous considered, one might think that enough evidence to tackle obesity is not yet available. However, a quick search on PubMed with the words "obesity prevention" indicates just the opposite. As by January 2017, it yielded close to 41,000 references, with a ratio of publications per year that has evolved from less than 300 in the mid-nineties to more than 3,500 in the last two years. Thus, it is not that there is a lack of evidence, but that, considering the intrinsic complexity of the obesity pandemic; this evidence is not adequate or easily translated into policy. From the late nineties, the emergence of evidence-based medicine overflowed the clinical field and policymakers were also required to found their work on sound data. ${ }^{4-14}$ The need for evidence-based policy is difficult to argue. However, the actual development of evidence-based policies is certainly challenged by a poor fit between atomized academic research, rigid evaluation standards, and the complex needs of policymakers. Since environmental actions progress according to a different timing: every intervention generates a series of events with different results that provide different indicators. ${ }^{19,20}$ It means that the ultimate effect of an intervention (i.e. obesity reduction) may not be noticeable until decades later, but it produces other changes in terms of knowledge or behaviours that can be measured over time. Besides, these furthest 
outcomes are exposed to so many influences, that when it comes to their evaluation it is difficult to establish cause-effect relationships. Because of that, some authors argue that currently accepted evidence levels are not sufficient or necessarily appropriate to determine good practices. ${ }^{21-27}$ These and others considerations belong to a growing consensus on the need of developing new approaches to define and interpret evidence in public health. Green \& Tones use the term "judicial review" to describe a triangulation-based process in which the final evaluation is made after exhaustively review all the evidence gathered through different methods. Other authors, like McNeil \& Flynn $^{22}$ or Brennan et al., ${ }^{28}$ develop similar approaches which, on a general basis, we can refer to it as an ecological method of research. ${ }^{29}$ If, to tackle obesity, systemic, holistic, ecological and evidence-based policies must be implemented, then more adequate methodological designs of evaluation are required. The aim of this article is to critically review to what extent childhood obesity prevention policies developed at different international levels have succeed at effectively translate current research into practice as well as to discuss how the evidence available can serve policy makers, with a focus on the specific case of Spain. With that intention, a review of reviews on childhood obesity prevention practices is first presented to identify the main recommendations on that field. Secondly, the most relevant policies implemented at different International institutional levels affecting Spain were reviewed to assess how they match the scientific literature recommendations. The emphasis on the need for a quick and effective response to the obesity alarming situation has entailed many initiatives and much research to find successful solutions. For this reason, numerous reviews on this topic have been published with a double intention: on the one hand, assessing the effectiveness of those actions, and on the other, providing evidence-based recommendations that allow the creation of successful and cost-effective interventions [30]. In our study, the choice of a tertiary level research such as reviewing reviews has been made to optimise the ability to synthesise the prevailing state-of-the-art on childhood obesity prevention, given the proliferation in the last years of systematic and other types of reviews in public health. Moreover, a review of reviews is an accepted practice in the medical and health behaviour literature. ${ }^{3-31}$

\section{Methods}

To identify current research recommendations on childhood obesity prevention, a search of systematic reviews and meta-analysis published from 2004 to 2015 using the search words "obesity", "overweight", "prevention", "diet", "nutrition" and "effectiveness" alone or in combination was performed in the MEDLINE and ERIC databases. Limits were set to only include studies targeting children and youth.

\section{Inclusion criteria were}

i. Systematic reviews.

ii. Studies addressing eating habits alone or eating habits and physical activity/sedentary behaviours.

\section{iii. Exclusion criteria included}

\section{iv. Papers not written in English or Spanish}

v. Studies focused on specific populations in terms of socioeconomic status, race, disabilities, or other health conditions.

To be coherent with the ecological approach described above, no restrictions were made regarding to the setting of the interventions or the actors involved. In the cases in which updates of previous review were available only the most recent version was included. References of the selected papers were also searched for further studies, with a final sample of 22 papers. To select the relevant policies undertaken at the different institutional levels, different experts on childhood obesity prevention were consulted. Next, a search for official documents on the different institutions' websites was conducted.

\section{Results}

\section{Research recommendations for childhood obesity prevention}

Table 1 shows the descriptive data of the 22 systematic reviews included in our study as well as the characteristics of these interventions that have been related to their effectiveness. A preliminary point of consensus among these reviews is the need for more accurately designed experimental studies on the prevention of childhood obesity: very few studies provide cost-effectiveness data, and although some studies reveal positive findings, these present some methodological weak points. ${ }^{21-35}$ In addition to the design, another methodological aspect that needs to be taken into account is the development of reliable instruments, along with the collection of anthropometric data and diet records. ${ }^{35,36} \mathrm{~A}$ given study can have positive or negative results depending on the corporal parameter used. For example, skin folds provide different information than adjusted weight, ${ }^{33-38}$ so it is indispensable to agree on how obesity is defined and measured, as it will clearly affect the intervention outcomes and comparability between studies. Measurement of behavioural changes also needs to be agreed upon. It has been recommended to base interventions in a behavioural theory and to develop assessment tools based on them. Few studies build their actions upon those theories, and even those theory-founded programmes do not evaluate in relation to their framework. ${ }^{38}$ Some authors claim for longer follow-ups, which would allow assessing whether the changes last over time. ${ }^{32-41}$ Regarding intervention characteristics, most reviews report actions based on nutritional education. While leaflets or two-hour activities can improve knowledge, they have not shown to modify behaviours sustainably. In this context, long-term interventions that entail contact between the children and the people delivering the intervention appear to be more effective, because habit changes are difficult and require continual reinforcement. ${ }^{21-43}$ Beyond that, though, and in accordance with the socioecological approach, the most relevant aspect associated with successful actions is multidimensionality: those interventions tackling dietary along with physical activity aspects, both at the individual and environmental level, have reported the best results. ${ }^{21-45}$ The best age for interventions is not yet clear. Most reviews support the premise that primary-school age is appropriate, and most interventions have been conducted in this age range. However, more research is needed to confirm this hypothesis. ${ }^{35-43}$ In addition, particularly at young ages, habit changes do not directly depend on children but rather on the adults in their environment, principally parents, but also other relatives, neighbors, teachers, and canteen educators. As expected, family involvement emerges as a crucial aspect ${ }^{36-48}$ although a remaining major question concerns how they should be involved. ${ }^{21-39}$

\section{Public policies against childhood obesity at European level}

As we can observe in Table 2, actions against childhood obesity have been undertaken from all institutional levels: the WHO, the 
WHO Regional Office for Europe, the EU Commission and the Spanish government has developed wide-range policies aiming at offering an integral solution to the dramatic rise of obesity rates. It becomes evident, for example, in the fact that policies do not target only children -although encourage specific actions for this segment, but they offer a wider range of actions for all population. The overall goal of all the policies reviewed is dual: on one hand, they all seek to address non-healthy habits and sedentary behaviors. They all intend to increase fruit and vegetables consumption and physical activity practice while decreasing the consumption of saturated fats, sugar and refined products. On the other, there is a manifested resolution to connect and engage all society sectors towards the common goal of reducing obesity. In fact, all initiatives seek to improve lifestyle by

i. Promoting actions in different fields affecting individuals' health behaviours (food industry, education, media, advertising, etc.

ii. Stimulating relationships between the stakeholders in those sectors with the intention to facilitate and encourage the exchange of experiences and best practice procedures. These aims are obviously tackled differently depending on the institutional level: the role of the WHO is eminently consultative, which means that it will not

Table I Reviews on the effectiveness of intervention for childhood obesity prevention
Review Inclusion criteria

\section{Exclusion criteria}

display concrete actions, but will provide a solid evidence bases and counselling to the States and institutions with legislative competence on how to implement policies. Likewise, the European Commission has consistently worked towards establishing priorities and offering guidance to the member States, especially through the funding of an important body of researches about the causes of obesity and how to better redirect the current tendency. At this level, the European Commission has also developed regulations in areas under its competence, such as food labelling and marketing. The Spanish government policies are also built upon the principles of a socioecological approach. Their actions transcend far beyond the healthcare and educational areas, by combining actions in all those sectors of society playing a role in preventing obesity. Yet, these actions are developed to a very high level and it remains unclear how individuals have been involved. The NAOS Strategy has not been evaluated yet, although the instruments for its assessment have been developed since $2011 .^{2}$ Regarding the PERSEO programme, results have been modest-however, they yield significant directions on how to advance to reduce the prevalence of childhood obesity through a holistic approach.

and further research recommendations

\begin{tabular}{|c|c|c|}
\hline & $\begin{array}{l}\text { Documents published between } 2006 \text { and } \\
\text { January } 2012 \text {. }\end{array}$ & Studies focused exclusively \\
\hline & At least English language abstract. & on obese children or \\
\hline Sobol et al. ${ }^{43}$ & $\begin{array}{l}\text { RCTs of children and teenagers } \\
5 \text {-I8years old. } \\
\text { School-based interventions tested based } \\
\text { on their effect on BMI }\end{array}$ & $\begin{array}{l}\text { designed to treat eating } 32 \text { studies. } \\
\text { disorders or other medical } \\
\text { conditions. }\end{array}$ \\
\hline
\end{tabular}

Documents published between 2006 and January 2012

At least English language abstract.

on their effect on BM
Comprehensive studies, defined as "having all of the following intervention components: providing information on nutrition and physical activity, attitudinal changes, monitoring eating and physical activity, environmental modifications; and/or all the following lifestyle behavioral targets: increased physical activity, decreased sedentary activity, improved healthy eating and decreased unhealthy eating. Duration longer than I year. Involved parental support. Targeting children versus teenagers.
Documents published through August

II, 2012.

Intervention primarily implemented in the community setting.

Bleich et al. ${ }^{40}$ At least I year of follow-up after baselin RCT of children and adolescents aged 2-I8years old.

Studies reported differences in weight between the intervention and control groups.

Documents published through August II, 2012.

Conducted in high-income countries. RCT of children and adolescents aged Showell et al. ${ }^{61}$
Involving a significant family component or targeting children in their homes. Reporting effects on weight-related outcomes.
Articles published in languages other than English.

Studies targeted only

at overweight or obese or suffering a chronic condition.

Studies collecting only qualitative data. children or adolescents,
Combination of interventions implemented in multiple settings -including a school component- and focused on both die and
Studies targeting children with excess weight of other pre-existing medical 6 studies. conditions. physical activity. Longer follow-up.

Targeting children in middle school or younger.

9 studies.
Poor evidence that home-based child obesity prevention programs are effective. Additional research is needed to test home-based interventions, especially those including parenting strategies and addressing environmental influences. 
Table Continued..

\begin{tabular}{llll}
\hline Review & Inclusion criteria & Exclusion criteria & $\begin{array}{l}\text { Characteristics of the studies associated } \\
\text { with greater effectiveness } \\
\text { and further research recommendations }\end{array}$
\end{tabular}

Family-based models of interventions produce positive effect regarding weight loss in overweight children.

Documents published between 1975 and 2012.

Sung-Chan et al. ${ }^{48}$

RCT of family-based life-style control in children and adolescents aged 2-19. interventions of weight loss and weight Not in English.

Interventions based on behavioral approaches seen to be more effective that those based on systemic theories.

15 studies. More rigorous methodological designs can help to further understand the potential of the family systems approach.

Researchers should address the role of gender in family-based interventions, since it may give different meanings and actions towards bodily changes.

Documents published between 1998 and

2010.

Prospective studies evaluating the

effectiveness of an intervention on children aged I-I8, run in parallel with a control/comparison group. Studies describing community or school-

Studies not applicable to the general population and

Golley RK et al. ${ }^{59}$ based interventions that included a where the intervention nutrition or activity component and a behavior change component and involve parents or caregivers.

Studies with at least one objectively measured primary outcome or a selfreported subjective outcome assessed using a validated tool.

Documents published between 2004 and 2010.

Interventions with control group.

Niemeier et al. ${ }^{42} \quad$ Children and adolescents aged 2-19years old as intervention participants. Interventions with pre and post measurements in terms on BMI.

36 studies.

Interventions that require parent participation more effectively reduce body mass index. Longer interventions that involve parental participation appear to have greater success. Additional studies on how interventions on parents indirectly affect children's BMI are encouraged.

Interventions that tap into self-efficacy, intention self-regulation, intrinsic motivation, enjoyment, autonomy support and proxy efficacy for physical activity.

School-based randomized controlled or Not full text available. quasi-experimental studies.

Outcome other than

Van Stralen et al. ${ }^{62}$

Targeted energy balance behaviors.

energy balance-related

Children and adolescents aged 4-I8years. behaviors associated with

Written in English.

Conducted mediation analyses.
24 studies.

Interventions that tackle knowledge, attitude and habit improve dietary habits.

Social influence, social support and social norms and eating together may be promising aspects to work on.

Different strategies may be needed to change physical activity levels, with regard to dietrelated behaviors.

Interventions that promote moderate to vigorous exercise and the active engagement of the parents as a role models.

Interventions seem to be more successful if they are sensitive to cultural differences.

A significant factor in effectiveness may be the training and enthusiasm of the staff for the intervention.
Delivered in any setting for children under 5years old.

Children with underlying 7 studies causal morbidity. and/or achieve weight loss and/or manage weight gain. Interventions with 
Table Continued..

Review Inclusion criteria
Exclusion criteria

Sample
Characteristics of the studies associated with greater effectiveness and further research recommendations

Studies published between 1998 and

2008.

Prospective studies of any duration of a researcher-introduced intervention with control groups and objective pre- and

Golley et al. ${ }^{59}$ post- measures.

Interventions targeting parents to

Not English language.

Studies not applicable to 17 studies the general population. improve children's weight status, dietary and or/activity patterns targeting nutrition or physical activity AND a behavior change.

Controlled study design with or without randomization.

Interventions longer than 12 months targeting children younger than I8years old at the start of the study. Objective weight-related outcome measures weight, \% fat content, BMI, pondered index, skin-fold thickness, obesity and overweight prevalence.
Interventions for preventing childhood obesity or targeting specific populations.
55 studies.

Studies published between January 1995 and August 2008.

Focused on breastfeeding.

Targeting children 0-5years old.And Eating disorders. reporting anthropometric, diet, physical Obesity treatment. activity or sedentary behaviors outcomes.School-based interventions English language.

RCT of interventions that included child dietary intake as a behavior change target and as a measured primary or secondary Studies designed to treat outcome.

Hingle et al. ${ }^{47}$

Published between 1980 and 2008.

Targeting children and teenagers

obesity or targeting

children with specific

medical conditions.

24 studies.

2-I8years old and involving a parental component

Studies published between 1998 and July 2008.

Results nor applicable to
the general population.

López et al. ${ }^{46}$ old. Interventions to treat

Including direct or indirect measures of obesity.

body adiposity.
Interventions that include strategies that span the spectrum of the behavior change process. Interventions that use behavior change techniques to consider include specific goal setting, prompt self-monitoring and self-talk, encourage barrier identification, restructure the home environment, set graded tasks and provide contingent rewards.

Both interventions targeting one or multiple behavior changes.

Interventions need to be developed that can be embedded into ongoing practice and operating systems, rather than implementing interventions that are resource intensive and cannot be maintained long-term.

Programs have beneficial effects on BMI, particularly when targeted to children aged 6-12years old

More research should be carried out to distinguish which of the components of the interventions contributed the most to the positive changes. Until the moment, the following strategies seem the most promising: inclusion of healthy eating, physical activity and body image content on the school curriculum, increased physical activity hours at school, parent support and home activities, environments and cultural practices that encourage children to eat more healthily and be more active; involvement of teachers and school staff.

Interventions need to be sensitive to cultural and socioeconomic differences.

Interventions are effective when they target skills and competences, and not only knowledge. Most studies reporting modest results lacked a parental component that may be key More data on the cost-effectiveness of these interventions is required.

Studies using direct methods to involve parents are more likely to report positive results than those using indirect methods.

Strategies targeting parents may be more effective than those operating in schools. However, the understanding of the parenting strategies linked to positive results need to be improved.

Increasing physical activity time at school reports positive results.

Interventions should take into account the different cultural and socioeconomic backgrounds.

More research about the optimal duration, follow-up, and ways to implement multiple setting interventions need to be carried out. 
Table Continued..

\begin{tabular}{llll}
\hline Review & Inclusion criteria & Exclusion criteria & $\begin{array}{l}\text { Characteristics of the studies associated } \\
\text { with greater effectiveness } \\
\text { and further research recommendations }\end{array}$
\end{tabular}

\section{Brown \&}

Summerbell..$^{58}$

Studies that reported a weight outcome. RCT or controlled clinical trial of lifestyle Not English language. interventions set in school for children Studies targeting children aged 5-18years old and of at least 12 weeks of duration.
38 studies with critical illnesses or eating disorders.
Studies published up to November 2007.

Interventions at pre-, primary or secondary Non-school setting.

Jaime \& Lock ${ }^{32}$ Interventions that promote changes in the environment, beyond nutritional education.
Studies targeting specific populations.

18 studies

Physical activity interventions may be more effective in younger children and girls. Gender differences need to be taken into account. There is insufficient evidence to elucidate whether physical activity interventions are more or less effective than dietary interventions, but the combination of both seems effective to prevent weight gain at least in the short term.

Longer interventions that include environmental changes that remain after the intervention get better results.

There is a need to foster programs evaluation, especially in the follow-up.

Evidence suggests that girls may respond better to educational components grounded based upon social learning, while boys may be more influenced by structural and environmental changes facilitating increased physical activity 2005

Kropski et al. ${ }^{33}$

Experimental or quasi experimental Studies on obesity

Studies published between 1990 and 2005 in English language

Sharma ${ }^{36} \quad$ Interventions conducted outside the United States targeting children 3-18years old. studies targeting children 4-I4years old. treatment. $\mathrm{BMI}$ as a primary or secondary outcome. Duration longer than 6 months.
Studies published in no peer reviewed journals. Interventions targeting only obese children.
I4 studies. and improved diet intake.

Long interventions targeting I0-I4years old seemed to obtain better results.

Further research is needed to determine whether involve parents is a cost-effective strategy.

Studies targeting primary school children and based in some behavioral theory seem more effective.

Interventions yield better results when parents are involved.

More research is needed to elucidate whether one component or multicomponent interventions are more effective.

The interventions reported in the studies that focused on health education and/or lifestyle behavioral changes e.g. eating habits, physical activity were reported to be effective.

Interventions addressing 2006 students with specific

Interventions conducted in Chinese kinder gardens or schools.

\section{medical conditions.}

22 estudies None of the trials identified by this systematic review demonstrated convincing evidence of the efficacy of any single intervention for the prevention of overweight and obesity in children and adolescents from Mainland China.

Most of the interventions focused on behavioral changes at the individual level, such as physical activity and nutrition, or TV watching. Further research is needed if interventions are more effective when targeting one specific behavior or when they address a combination of them. Anyway, it seems clear that both diet and physical activity need to be addressed.

Published in English.

Published between 1999 and 2004.

Sharma $^{39} \quad$ Conducted in the USA or UK.

Addressed not only to obese children.

Having an explicit school-based

curriculum for prevention of obesity.
I I studies Interventions targeting children below IOyears old seem to be more effective.

Most of the studies are based upon some behavioral theory, but behavioral changes are, in general, poorly documented. More efforts to develop instruments that measure them are needed.

Few studies involve families, although this is a potentially promising approach.

School interventions need to be reinforced with environmental changes and local policies. 
Table Continued..

\begin{tabular}{|c|c|c|c|c|}
\hline Review & Inclusion criteria & Exclusion criteria & Sample & $\begin{array}{l}\text { Characteristics of the studies associated } \\
\text { with greater effectiveness } \\
\text { and further research recommendations }\end{array}$ \\
\hline Doak et al. ${ }^{37}$ & $\begin{array}{l}\text { Published until } 2005 . \\
\text { Interventions targeting school age } \\
\text { children. } \\
\text { Interventions with pre- and post- body } \\
\text { measures. } \\
\text { Interventions targeting diet and/or } \\
\text { physical activity. }\end{array}$ & $\begin{array}{l}\text { Studies with a documented } \\
\text { monitorization and } \\
\text { evaluation. } \\
\text { Non-obesity related } \\
\text { studies. } \\
\text { Interventions addressed } \\
\text { only to obese children. }\end{array}$ & 25 studies & $\begin{array}{l}\text { There is a need for more research with more } \\
\text { rigorous designs. Until the moment, primary } \\
\text { school interventions seem to be more } \\
\text { appropriate. } \\
\text { Physical education in schools and reducing } \\
\text { television viewing are two examples of } \\
\text { interventions that have been successful. } \\
\text { Gender, ethnicity and culture need to be } \\
\text { taken into account since are likely to affect } \\
\text { interventions' results. }\end{array}$ \\
\hline Flynn et al. ${ }^{21}$ & $\begin{array}{l}\text { Published between } 1982 \text { and } 2003 . \\
\text { Studies reporting on outcome weight, } \\
\text { comorbidity, risk factors and process } \\
\text { indicators. }\end{array}$ & $\begin{array}{l}\text { Program reports } \\
\text { associated with marketing } \\
\text { products. } \\
\text { Foreign language reports } \\
\text { that did not include English } \\
\text { abstract. } \\
\text { Case studies, surgical } \\
\text { interventions. } \\
\text { Participants older than } \\
\text { I7years old. } \\
\text { Participants with physical } \\
\text { or mental health issues. }\end{array}$ & I 47 studies & $\begin{array}{l}\text { Health education on healthy diet and physical } \\
\text { activity was the most common intervention. } \\
\text { Environmental interventions were infrequent. } \\
\text { There is a need to develop validated measures } \\
\text { to assess behavioral changes. Self-evaluations are } \\
\text { susceptible of producing biased results. } \\
\text { There are several methodological limitations } \\
\text { that hinder the validity of the results of the } \\
\text { paper reviewed. } \\
\text { There is a lack of long-term studies that makes } \\
\text { difficult to confirm behavioral changes in the } \\
\text { youth after the interventions. } \\
\text { Few studies consider the role of a leader as } \\
\text { something conditioning the success of the } \\
\text { program, but it seems a promising strategy. } \\
\text { Few studies address psychosocial variables. } \\
\text { There is a gap of specific interventions for some } \\
\text { groups, namely 0-5y old, immigrants, and boys. } \\
\text { Schools emerge as a pivot in childhood obesity } \\
\text { prevention. On the other hand, studies regarding } \\
\text { the family setting are lacking. }\end{array}$ \\
\hline
\end{tabular}

Table 2 Childhood obesity policies implemented at different institutional levels affecting spain

$\begin{array}{llll}\text { Name Institution } & \text { Major aims } & \text { Objectives } & \begin{array}{l}\text { Other key } \\ \text { questions }\end{array}\end{array}$

Global

\section{Strategy on}

Diet, Physical WHO, in response to the request

Activity

and Health, World Health Assembly 2002.

2004WHO ${ }^{63}$

made by the Member States in the
To provide a wide range of global policy options for all sectors WHO, States, International Associates, Private Sector and Civil Society to address nonhealthy habits and sedentary behaviours.
To reduce risk factors for unhealthy diet and sedentary behaviour-related chronic diseases through the development of Public Health actions.

To raise awareness and understanding on diet and physical activity influences on health and the potential positive effect of preventive action.

To develop, reinforce and implement policies at the global, national and regional level, as well as sustainable action plans to improve diet and physical activity levels that actively involve all sectors.

To promote research in healthy eating and physical activity.
Given the consultive role of the $\mathrm{WHO}$,

It enunciates responsibilities for each of the stakeholders involved $\mathrm{WHO}$ the main endeavor undertaken under the umbrella of the Global Strategy consist of activities States, International that intend to Associates, Private encourage States and No. Sector and Civil other stakeholders Society and to develop formulates specific and implement recommendations. comprehensive policies to prevent non-communicable diseases. 
Table Continued..

Name

European

Charter on Counteracting together with the European Obesity, 200665 Commission

EU Action Plan

on Childhood European Commission, in Obesity 20I4- coordination with the WHO. $2020^{66}$
To place obesity

among the

priorities of

Public Health

and other

sectors political

agendas and to To help WHO European

promote greater countries:

awareness To evaluate their needs.

and political To assess current state,

engagement. tendencies and policies.

To provide

political

To gather and analyse

orientation

evidence of intervention

to strengthen

effectiveness.

To consolidate a as well as facilitate global

framework that agreements in the fight

connects main against obesity.

actors, policies

and actions at

different levels,

promoting

synergies and

avoiding overlaps.
It claims political

commitment and

governmental

leadership to

mobilise and create

synergies between

the different social

actors.

It set goals to

be achieved and

principles and

guidelines to reach

them.

It recognises the

value of working at

the local level.

It reminds us that

every policy -

economic, agrarian,

transport- has an

impact on health.
According to its

advisory role,

providing guidance

and support to the No

Member States based

on updated evidence.
To demonstrate

the shared

commitment

of EU Member The Plan, which strongly

States to address emphasises Member States

childhood exclusive competence in

obesity; to set defining national health

out priority areaspolicies, sets out eight priorityObesity-related

for action and a areas for various stakeholders Health Issues 2007,

possible toolbox to:

the Action Plan

of measures for Support a healthy start in life benefits from the

consideration Promote healthier its evaluation and

and to propose environments, especially in applies a much more

ways of schools and pre-schools

comprehensive

collectively Make the healthy option the approach on the

keeping track of easier option

causes and health

progress - while Restrict marketing and effects of childhood

recognizing

Member

States' roles

and freedom

of action in

advertising to children

obesity, poor

Inform and empower families diet and physical

Encourage physical activity inactivity, and

Monitor and

how these can be

Increase research

operationalized.
It counts with

a complete set

of operational

objectives and

indicators to be

applied at the

end of 2020.

Additionally, a

No data available yet. review of the objectives and actions described in 2014 is foreseen to be done every threeyears to stablish whether some redirection is necessary.

childhood

obesity. 
Table Continued.

\begin{tabular}{llll}
\hline Name Institution & Major aims & Objectives & Other key \\
questions & Actions & Endertaken
\end{tabular}

White paper, European Commission, from "A Strategy the Green Paper "Promoting on Nutrition, healthy diets and physical activity: Overweight, a European dimension for the and Obesity- prevention of overweight, obesity related health and chronic diseases" and the EU issues" $2007^{67}$ platform for action on diet, physica activity and health.

\section{NAOS}

strategy, 2005

Strategy for Ministry of Health and Consumer

Nutrition, Affairs, through the Spanish Agency

Physical for Food Safety and Nutrition

Activity and AESAN

the Prevention

of Obesity ${ }^{68}$

\section{It is mainly focused on measures that affect EU \\ fields of competence; thus, the measures are primarily legislative and economic:}

a. To regulate advertising especially that addressed to children and nutritional labelling.

To complement and optimise national and local actions, as well as address some issues of the European Commission competence. To combine local and national actions of common interest and set mechanisms to share good practices. promulgating laws to promote a greater consumption of unprocessed food and more regular physical activity practice, for example, encouraging bicycle use as a transportation.
To address the current Spanish obesity situation through an approach that involves families, communities, schools, health centers and the private sector. b. To give options for a healthier lifestyle regular means of

c. To give priority to childhood obesity, especially through environmental actions, with the support of teachers and families and in cooperation with local and national governments. To establish a communitarian system to monitor and evaluate actions.

To change obesity tendencies and to prevent the development of obesity as well as that of eating disorders

To make people aware of the benefit of, and to promote, a healthy diet and the practice of physical activity as a mean to maintain energy balance. To work with the food industry to promote healthie products.

To promote health professional awareness to systematically assess and $t$ is developed under the assumptions that: As a last resort, each individual is responsible for his her lifestyle and his/her children's lifestyle.

Only a wellinformed consumer can make wellreasoned decisions. Integral responses involving different sectors and levels are needed to develop effective responses to the current situation.

(n)

(1)

\begin{tabular}{|c|c|}
\hline & Independent \\
\hline Creation of the & external evaluation \\
\hline High Level Group & in $2012 / 2013$ \\
\hline on Nutrition and & The results of \\
\hline Physical Activity3 I & this evaluation \\
\hline and the EU Platform & were positive \\
\hline for Action on Diet, & and support \\
\hline Physical Activity and & continuation of \\
\hline Health as primary & the Strategy and \\
\hline instruments set up & its However, it \\
\hline for implementation & was determined \\
\hline of the Strategy. & that to ensure a \\
\hline Formulation of & more balanced \\
\hline $\begin{array}{l}\text { policies regarding } \\
\text { food labelling, }\end{array}$ & $\begin{array}{l}\text { response, greater } \\
\text { focus is now }\end{array}$ \\
\hline nutrition and health & needed on physical \\
\hline claims, the Common & activity promotion. \\
\hline Agricultural Policy & Continued \\
\hline CAP and the & coordination at \\
\hline transport, urban & $\begin{array}{l}\text { the EU-level by } \\
\text { the European }\end{array}$ \\
\hline and culture sectors, & Commission also \\
\hline as well as research & remains necessary \\
\hline $\begin{array}{l}\text { projects in physical } \\
\text { activity, nutrition an }\end{array}$ & to facilitate \\
\hline health & $\begin{array}{l}\text { children and young } \\
\text { people. }^{70}\end{array}$ \\
\hline
\end{tabular}
follow obesity.

To promote obesity-related research to find effective ways to prevent and treat obesity.

Development of specific regulations for the advertising t promotes action of food products for to bring obesity children - Código prevention to local PAOS. agendas. It develops preventive actions targeting publicity and marketing addressed to children.
A set of indicators Launch of several was developed in publications on $201 \mathrm{I}$ to monitor healthy eating and and assess the physical activity for strategy, but it has different targets not been applied Agreements with yet. the private sector for the formulation of healthier food products. 
Table Continued.

\begin{tabular}{|c|c|c|c|c|c|c|}
\hline Name & Institution & Major aims & Objectives & $\begin{array}{l}\text { Other key } \\
\text { questions }\end{array}$ & $\begin{array}{l}\text { Actions } \\
\text { undertaken }\end{array}$ & Evaluation \\
\hline $\begin{array}{l}\text { PERSEO } \\
\text { Programme, } \\
2006 \\
\text { Pilot } \\
\text { Programme } \\
\text { in Schools } \\
\text { for Health } \\
\text { and Physical } \\
\text { Exercise } \\
\text { and against } \\
\text { Obesity }{ }^{69}\end{array}$ & $\begin{array}{l}\text { Spanish Ministries of Health, Social } \\
\text { Services and Equality and the } \\
\text { Ministries of Education, Culture and } \\
\text { Sports }\end{array}$ & $\begin{array}{l}\text { As a NAOS } \\
\text { Strategy in } \\
\text { schools, it aims } \\
\text { to promote } \\
\text { the learning of } \\
\text { healthy eating } \\
\text { habits and to } \\
\text { encourage } \\
\text { regular physical } \\
\text { activity among } \\
\text { schoolchildren to } \\
\text { prevent obesity. }\end{array}$ & $\begin{array}{l}\text { To promote the development } \\
\text { of a healthy lifestyle among } \\
\text { scholars to prevent childhood } \\
\text { obesity. } \\
\text { To detect childhood } \\
\text { obesity early and avoid its } \\
\text { progression through clinical } \\
\text { assessment in primary health } \\
\text { care. } \\
\text { To raise awareness on the } \\
\text { important role of educators } \\
\text { To create a school and family } \\
\text { environment that favours } \\
\text { healthy eating and regular } \\
\text { physical activity practice. } \\
\text { To design indicators to be } \\
\text { applied and assessed easily. }\end{array}$ & $\begin{array}{l}\text { It purports that its } \\
\text { dactions also reach } \\
\text { families and plans } \\
\text { actions to make } \\
\text { healthy food choices } \\
\text { easier to make; it } \\
\text { is also present in } \\
\text { school canteens. } \\
\text { Its first results } \\
\text { have shown a } \\
\text { modest reduction } \\
\text { of the prevalence } \\
\text { of obesity and a } \\
\text { greater change of } \\
\text { habits among the } \\
\text { scholar-participants. }\end{array}$ & $\begin{array}{l}\text { Development of } \\
\text { guides on healthy } \\
\text { s eating for famílies, } \\
\text { schools, Health } \\
\text { professionals and } \\
\text { children. } \\
\text { Organization of } \\
\text { workshops for } \\
\text { teachers, famílies and } \\
\text { class activities for } \\
\text { children. }\end{array}$ & $\begin{array}{l}\text { Significant } \\
\text { improvement of } \\
\text { physical activity } \\
\text { levels and diet } \\
\text { quality. } \\
\text { Modest results } \\
\text { on the prevalence } \\
\text { of obesity, which } \\
\text { increases during } \\
\text { the study, but less } \\
\text { than in the control } \\
\text { group. }\end{array}$ \\
\hline
\end{tabular}

\section{Discussion}

Tackling childhood obesity is a serious public health issue and a major concern worldwide, as evident in the numerous actions undertaken by different institutions. In the last years, a vast theoretical comprehension of the phenomenon, as well as a growing social awareness has been achieved, but, in practice, the situation has not significantly improved. ${ }^{5-49}$ Current understanding of obesity, as well as recent investigations support a holistic approach that extends beyond mere education and involves different stakeholders at the individual, social and environmental levels. At this point, obesity is a social issue that will only be solved with strong policy actions. However, policymakers face numerous barriers to work on this direction, one of the most relevant being the difficulty of implementing systemic policies based upon compartmentalised research. ${ }^{6-50}$ On paper, the policies analysed in this study comply with and incorporate research recommendations, attempting to offer an integral response to the current situation; but in practice there is a gap in how to reach these goals, as well as a functional overlap of objectives and actions between the different institutional levels. Actions need more definition, particularly in the procedural and methodological aspects. In most cases, the target for these actions is not clear, nor is it how the message will arrive or how it will change attitudes and behaviours. These observations are valid in the case of Spain, and, considering the different levels of competence, in the case of upper institutions too. In order to optimise resources, it is essential to connect the different institutional levels so that each one has well-defined competencies, objectives and actions. By avoiding duplications, a better resource distribution is favoured and a greater scope of and/or more intense actions can be launched. In other words, childhood obesity prevention must move towards the milestone set in the European Charter on Counteracting Obesity, which is to consolidate a framework that connects the main stakeholders, policies and actions taken at different levels and that enables the enhancement of the capabilities of each contributor. ${ }^{6-51}$ Our results indicate that we have enough evidence to know what to do, but we still need to figure out how to implement these actions in a coordinate and sustainable way. From our perspective, a lot can be learned by examining how these local partnerships have been developed in other fields. For example, collaborative networks have demonstrated to be a valuable tool to improve educational achievement, innovative capacities and a greater organizational capacity at the community level, ${ }^{52-56}$ and given the common characteristics of those phenomena with childhood obesity, they may well serve as inspiration for the development and implementation of more comprehensive models of intervention in public health.

\section{Acknowledgements}

None.

\section{Conflict of interest}

Author declares that there is no conflict of interest.

\section{References}

1. Ng M, Fleming T, Robinson M, et al. Global, regional, and national prevalence of overweight and obesity in children and adults during 1980 2013:a systematic analysis for the Global Burden of Disease Study 2013. Lancet. 2014;384(9945):766-781.

2. Ballesteros JM. Evaluation and Monitoring of the NAOS Strategy: Minimum Set of Indicators. Madrid, Spain; 2011. p. 1-51.

3. Biddle SJ, Asare M. Physical activity and mental health in children and adolescents: a review of reviews. Br J Sports Med. 2011;45(11):886895 .

4. Black N, Donald A. Evidence based policy: proceed with care. BMJ. 2001;323(7307):275-279.

5. Gortmaker SL, Swinburn BA, Levy D, et al. Changing the future of obesity: Science, policy, and action. Lancet. 2011;378(9793):838-847.

6. Kumanyika S, Libman K, Garcia A. Strategic Action to Combat the Obesity Epidemic. UK; 2013. p. 1-48.

7. Roberto CA, Swinburn B, Hawkes C, et al. Patchy progress on obesity prevention: emerging examples, entrenched barriers, and new thinking. Lancet. 2015;385(9985):2400-2409.

8. Swinburn B, Kraak V, Rutter H, et al. Strengthening of accountability systems to create healthy food environments and reduce global obesity. Lancet. 2015;385(9986):2534-2545.

9. Swinburn B, Vandevijvere S, Kraak V, et al. Monitoring and benchmarking government policies and actions to improve the healthiness of food environments: a proposed Government healthy food environment policy index. Obes Rev. 2013;14(Suppl 1):24-37. 
10. Coll JL, Bibiloni Mdel M, et al. Prevalence and related risk factors of overweight and obesity among the adult population in the Balearic Islands, a Mediterranean Region. Obes Facts. 2015;8(3):220-233.

11. Rozin P. The Meaning of food in our lives: a cross-cultural perspective on eating and well-being. J Nutr Educ Behav. 2005;37(Suppl 2):107112.

12. Terry TK Huang, Cawley JH, Ashe M, et al. Mobilisation of public support for policy actions to prevent obesity. Lancet. 2015;385(9985):24222431.

13. Terry TK Huang, Glass TA. Transforming research strategies for understanding and preventing obesity. JAMA. 2008; 300(15):1811-1813.

14. Hurst SA, Borisch B, Mauron A. Public health: How much evidence is needed to support our policies? J Public Health Policy. 2011;32(1):135141

15. Kleinert S, Horton R. Rethinking and reframing obesity. Lancet. 2015;385(9985):2326-2328.

16. Robbins A, Nestle M. Obesity as collateral damage: A call for papers on the obesity epidemic. J Public Health Policy. 2011;32(2):143-145.

17. Dufour DL, Goodman AH, Pelto GH. Nutritional Anthropology: Biocultural Perspectives on Food and Nutrition. USA: Oxford University Press; 2013. p. 1-532.

18. Yach D, McKee M, Lopez AD, et al. Improving diet and physical activity:12 lessons from controlling tobacco smoking. $B M J$. 2005;330(7496):898-900.

19. Green J, Tones K. Towards a secure evidence base for health promotion J Public Health Med. 1999;21(2):133-139.

20. Tones K. Measuring success in Health Promotion. Selecting indicators of performance. Hygie. 1992;11(4):10-14.

21. Flynn MAT, McNeil DA, Maloff B, et al. Reducing obesity and related chronic disease risk in children and youth: a synthesis of evidence with 'best practice' recommendations. Obes Rev. 2016;7(Suppl 1):7-66.

22. Mcneil DA, Flynn MA. Methods of defining best practice for population health approaches with obesity prevention as an example. Proc Nutr Soc. 2006;65(4):403-411.

23. Swinburn B, Gill T, Kumanyika S. Obesity prevention: a proposed framework for translating evidence into action. Obes Rev. 2005;6(1):23-33.

24. Tannahill A. Beyond evidence-to ethics: a decision-making framework for health promotion, public health and health improvement. Health Promot Int. 2008;23(4):380-390.

25. Tannahill A, Kelly MP. Layers of complexity in interpreting evidence on effectiveness. Public Health. 2013;127(2):164-170.

26. Victora CG, Habicht JP, Bryce J. Evidence-based public health: moving beyond randomized trials. Am J Public Health. 2004;94(3):400-405.

27. WHO. The Ottawa Charter for Health Promotion. Geneva; 1986. p. 1-5.

28. Brennan L, Castro S, Brownson RC, et al. Accelerating evidence reviews and broadening evidence standards to identify effective, promising, and emerging policy and environmental strategies for prevention of childhood obesity. Annu Rev Public Health. 2011;32:199-223.

29. McLaren L, Hawe P. Ecological perspectives in health research. J Epidemiol Community Health. 2005;59(1):6-14.

30. Green BN, Johnson CD, Adams A. Writing narrative literature reviews for peer-reviewed journals: secrets of the trade. J Chiropr Med. 2006;5(3):101-117.

31. Hillsdon M, Foster C, Naidoo B, et al. The effectiveness of public health interventions for increasing physical activity among adults : A review of reviews. Evidence briefing. 2004. 4 p.
32. Jaime PC, Lock K. Do school based food and nutrition policies improve diet and reduce obesity? Prev Med. 2009;48(1):45-53.

33. Kropski JA, Keckley PH, Jensen GL. School-based obesity prevention programs: an evidence-based review. Obesity (Silver Spring). 2008;16(5):1009-1018.

34. Li M, Li S, Baur LA, et al. A systematic review of school-based intervention studies for the prevention or reduction of excess weight among Chinese children and adolescents. Obes Rev. 2008;9(6):548-559.

35. Waters E, De Silva-Sanigorski A, Hall BJ, et al. Interventions for preventing obesity in children. Cochrane Database of Systematic Reviews. 2011.

36. Sharma M. International school-based interventions for preventing obesity in children. Obes Rev. 2007;8(2):155-167.

37. Doak CM, Visscher TL, Renders CM, et al. The prevention of evereight and obesity in children and adolescents: a review of intervetions and programmes. Obes Rev. 2006;7(1):111-136.

38. Hesketh KD, Campbell KJ. Interventions to prevent obesity in $0-5$ year olds: an updated systematic review of the literature. Obesity (Silver Spring). 2010;18 (Suppl 1):S27-S35.

39. Sharma M. School-based interventions for childhood and adolescent obesity. Obesity Rev. 2006;7(3):261-269.

40. Bleich SN, Segal J, Wu Y, et al. Systematic review of community-based childhood obesity prevention studies. Pediatrics. 2013;132(1):e201e210.

41. Williams AJ, Henley WE, Williams CA, et al. Systematic review and meta-analysis of the association between childhood overweight and obesity and primary school diet and physical activity policies. Int J Behav Nutr Phys Act. 2013;10:101.

42. Niemeier BS, Hektner JM, Enger KB. Parent participation in weightrelated health interventions for children and adolescents: a systematic review and meta-analysis. Prev Med. 2012;55(1):3-13.

43. Sobol-Goldberg S, Rabinowitz J, Gross R. School-based obesity prevention programs: a meta-analysis of randomized controlled trials. Obesity (Silver Spring). 2013;21(12):2422-2428.

44. Brug J, Van Stralen MM, Te Velde SJ, et al. Differences in weight status and energy-balance related behaviors among schoolchildren across Europe: the ENERGY-project. PLoS One. 2012;7(4):e34742.

45. Hendrie Ga, Brindal E, Corsini N, et al. Combined home and school obesity prevention interventions for children:what behavior change strategies and intervention characteristics are associated with effectiveness? Health Educ Behav. 2012;39(2):159-171.

46. Lopez L, Audisio Y, Berra S. Effectiveness of population-based interventions aimed at preventing overweight in children and adolescents. Med Clin. 2010;135(10):462-469.

47. Hingle MD, Connor TMO, Dave JM, et al. Parental involvement in interventions to improve child dietary intake: A systematic review. Prev Med. 2010;51(2):103-111.

48. Sung-Chan P, Sung YW, Zhao X, et al. Family-based models for childhood-obesity intervention: a systematic review of randomized controlled trials. Obes Rev. 2013;14(4):265-278.

49. Swinburn B, Sacks G, Hall KD, et al. The global obesity pandemic: shaped by global drivers and local environments. Lancet. 2011;378(9793):804-814.

50. Lobstein T. Child obesity: what can be done and who will do it? Proc Nutr Soc. 2008;67(3):301-306.

51. WHO (2012) Prioritizing Areas for Action in the Field of PopulationBased Prevention of Childhood Obesity. Geneva, pp. 1-86. 
52. Civís M, Longas E, Longás J, et al. Education, territory and community development: emerging practices. Soc Edu. 2007;36:13-25.

53. Díaz-Gibson J, Civís M. Socio-Educational Networks enhancing community social capital: A theoretical reference framework. Childhood and Learning Foundation. 2011;23(3):415-429.

54. Renée M, McAlister S. The strengths and challenges of community organizing as an education reform strategy: what the research Says. Quincy, Massachusetts:Nellie Mae Education Foundation. USA; 2011. p. 1-35.

55. Sorensen E, Torfing J. Enhancing collaborative innovation in the public sector. Administration \& Society. 2011;43(8):842-868.

56. Carpenter H, Cummings C, Dyson A, et al. Extended Services Evaluation: End of Year One Report. USA; 2010. p. 1-212.

57. Bond M, Wyatt K, Lloyd J, et al. Systematic review of the effectiveness of weight management schemes for the under fives. Obes Rev. 2011;12(4):242-253.

58. Brown T, Summerbell C. Systematic review of school-based interventions that focus on changing dietary intake and physical activity levels to prevent childhood obesity:an update to the obesity guidance produced by the National Institute for Health and Clinical Excellence. Obes Rev. 2009;10(1):110-141.

59. Golley RK, Hendrie GA, Slater A, et al. Interventions that involve parents to improve children's weight-related nutrition intake and activity patterns-what nutrition and activity targets and behaviour change techniques are associated with intervention effectiveness? Obes Rev. 2011;12(2):114-130.

60. Hillier F, Pedley C, Summerbell C. Evidence-base for primary prevention of obesity in children and adolescents. Bundesgesundheitsblatt Gesundheitsforschung Gesundheitsschutz. 2011;54(3):259-264.
61. Showell NN, Fawole O, Segal J, et al. A systematic review of home-based childhood obesity prevention studies. Pediatrics. 2013;132(1):e193e200.

62. Van Stralen MM, Yildirim M, Te Velde SJ, et al. What works in schoolbased energy balance behaviour interventions and what does not? A systematic review of mediating mechanisms. Int $J$ Obes (Lond). 2011;35(10):1251-1265.

63. WHO. Global Strategy on Diet, Physical Activity and Health. Geneva; 2004. p. 1-21.

64. WHO. Obesity: preventing and managing the global epidemic. Report of a WHO consultation. World Health Organ Tech Rep Ser. 2000;894:1253.

65. WHO. European Ministerial Conference on Counteracting ObesityDiet and physical activity for health. Europe; 2006. p. 1-36.

66. European Commision. EU Action Plan on Childhood Obesity 20142020. Europe; 2014. p. 1-68.

67. European Commission. White Paper on a Strategy for Europe on $\mathrm{Nu}$ trition, Overweight and Obesity related health issues. Europe; 2007. p. $1-12$.

68. Neira M, De Onis M. The Spanish strategy for nutrition, physical activity and the prevention of obesity. Br J Nutr. 2007;96 (Suppl 1):8-11.

69. Perez-Rodrigo C, Calderon V, Campos Amado J, et al. Project: Process evaluation, level of implementation and effectiveness. Annals of Nutrition and Metabolism. 2013;63:1115.

70. Public Health Evaluation and Impact Assessment Consortium. Evaluation of the implementation of the Strategy for Europe on Nutrition, Overweight and Obesity related health issues. 2013. p. 1-166. 